\title{
Enhancing stocks of the exploited limpet Patella candei d'Orbigny via modifications in coastal engineering
}

\author{
Gustavo M. Martins ${ }^{\mathrm{a}, \mathrm{b}, \mathrm{c}, *}$, Richard C. Thompson ${ }^{\mathrm{b}}$, Ana I. Neto ${ }^{\mathrm{a}, \mathrm{d}}$, Stephen J. Hawkins ${ }^{\mathrm{c}, \mathrm{e}}$, Stuart R. Jenkins ${ }^{\mathrm{c}, \mathrm{e}}$ \\ a Secção Biologia Marinha, Departamento Biologia, Universidade dos Açores, 9501-801 Ponta Delgada, Açores, Portugal \\ ${ }^{\mathrm{b}}$ Marine Biology and Ecology Research Centre, Marine Institute, University of Plymouth, Plymouth PL4 8AA, UK \\ ${ }^{\mathrm{c}}$ Marine Biological Association, Citadel Hill, Plymouth PL1 2PB, UK \\ ${ }^{\mathrm{d}}$ Centro Interdisciplinar de Investigação Marinha e Ambiental (CIIMAR), Rua dos Bragas 289, 4050-123 Porto, Portugal \\ ${ }^{\text {e }}$ School of Ocean Sciences, Bangor University, Menai Bridge, Anglesey LL59 5AB, UK
}

\section{A R T I C L E I N F O}

Article history:

Received 24 March 2009

Received in revised form 22 September

2009

Accepted 7 October 2009

Available online 30 October 2009

\section{Keywords:}

Microhabitat

Coastal urbanisation

Patterns of distribution

Limpet harvesting

Seawall

Azores

\begin{abstract}
A B S T R A C T
It is widely recognised that microhabitats are important for a variety of marine organisms, yet this knowledge has rarely been applied in the construction of engineered structures as a means of enhancing biodiversity or populations of species at risk. Here we examined the influence of microhabitats on the distribution and survival of the exploited limpet Patella candei on natural shores before determining the effect of introducing such habitats to an artificial seawall. On natural shores individuals were associated with pits (a natural feature of volcanic rocky shores). Animals inhabiting pits showed reduced mortality and were smaller than those on open rock. Microhabitat utilisation was similar over the vertical range of distribution of $P$. candei. Following observation of natural patterns, we applied this knowledge by experimentally drilling pits at varying densities and sizes in a seawall that had been constructed with simple topographical complexity. Overall, the number of animals increased in areas with experimentally increased microhabitat area. There was evidence that this was the result of immigration (larger animals) but also of increased recruitment. This study demonstrates one cost-effective way of conciliating the need to protect our coastlines while promoting the conservation and stock enhancement of overexploited species.
\end{abstract}

(c) 2009 Elsevier Ltd. All rights reserved.

\section{Introduction}

Coastal systems are highly productive but their accessibility has rendered them susceptible to a variety of anthropogenic impacts (Thompson et al., 2002) and there is increasing appreciation that a wide range of human activities have altered or degraded coastal marine ecosystems. Exploitation of living marine resources is one such activity, which, through direct and indirect effects can affect the trophic structure of marine ecosystems (e.g. Botsford et al., 1997; Castilla, 2000).

The management of fisheries stocks has mainly been via restrictive or precautionary measures, among which, the establishment of quotas, minimum catch sizes or the implementation of no-take marine reserves and closed seasons are the most common. In addition, alternative and more proactive measures such as the deliberate release of cultured animals have increased in recent years

\footnotetext{
* Corresponding author. Address: Secção Biologia Marinha, Departamento Biologia, Universidade dos Açores, 9501-801 Ponta Delgada, Açores, Portugal. Tel.: +351 296650 000; fax: +351296650100.

E-mail addresses: gustavo.martins@plymouth.ac.uk (G.M. Martins), r.c.thompson@plymouth.ac.uk (R.C. Thompson), aneto@uac.pt (A.I. Neto), s.hawkins@bangor.ac.uk (S.J. Hawkins), s.jenkins@bangor.ac.uk (S.R. Jenkins).
}

(Booth and Cox, 2003) despite some concern that this measure may have negative effects, for instance, by changing the genetic diversity of wild populations or introducing diseases (Bartley et al., 2006; Bell et al., 2006).

The deployment of artificial structures that increase habitat complexity in marine habitats or confer protection to certain life stages have been widely used with the purpose of enhancing fishery resources or the rehabilitation of habitat that has been lost. Successful examples exist for the stock enhancement in populations of rock lobsters (Butler and Herrnkind, 1997; Briones-Fourzán et al., 2007), fish (Santos and Monteiro, 1997; Leitão et al., 2008) and algae (Choi et al., 2002; Oyamada et al., 2008). The materials conventionally used as artificial reefs are mostly concrete blocks although other materials (e.g. waste vehicle tires) have also been tested. The potential use of such structures in enhancing the stocks of intertidal sedentary or sessile species (e.g. limpets, goose barnacles) has, however, been largely overlooked.

The deployment of artificial structures in coastal areas is, however, controversial. Worldwide urbanisation has resulted in substantial proportions of the coast being replaced by artificial structures such as marinas, breakwaters or seawalls (e.g. Sydney Harbour, Australia - Airoldi et al., 2005; Chapman, 2006) and much 
work has shown that coastal defence structures are poor surrogates for the natural habitats they replace (Chapman, 2003, 2006; Chapman and Bulleri, 2003; Moschella et al., 2005) and their impacts can extend to adjacent systems (Kelaher et al., 1998; Martin et al., 2005; Clynick et al., 2008; Martins et al., 2009). The predicted increase in storm frequency and sea-level rise due to global warming, as well as increased demands for renewable energy is however likely to exacerbate the number of artificial structures that will be deployed in coastal habitats (Thompson et al., 2002; Booth and Cox, 2003). Modifications to existing and proposed coastal engineering structures offer an opportunity for integrative management between the need to protect coastal areas or generate energy and the enhancement of biodiversity or stocks of exploited species (Moschella et al., 2005).

Conservation management of organisms that are currently under disturbance requires a sound understanding of the life-history and ecology of the target species. Intertidal animals such as limpets experience extreme environmental conditions during the low tide period (e.g. Lewis, 1964) associated with thermal and desiccation stresses (Harley, 2003). These animals, especially upper shore species, usually have high physiological tolerances (e.g. Wolcott, 1973) and exhibit a range of morphological (e.g. Vermeij, 1973; Branch and Marsh, 1978) and behavioural (e.g. Garrity, 1984; Williams and Morritt, 1995) adaptations which help to reduce the effects of environmental stress. For example, the selection of particular habitats such as crevices or pits can greatly reduce physical stress (Jones and Boulding, 1999) by allowing species to survive higher on the shore. Microhabitats are topographic features and are considered important refugia for a wide range of intertidal organisms by dampening environmental extremes (Fairweather, 1988; Gray and Hodgson, 1998) and providing protection from predation (Bertness et al., 1981; Garrity, 1984). Microhabitats can be provided by physical features such as crevices (Fairweather et al., 1984; Gray and Hodgson, 1998) and pits (Chapman, 1994; Underwood, 2004), or biological features such as the tests of living or dead barnacles (Underwood and McFadyen, 1983; Bros, 1987) and engineering species (Crowe, 1996; Thompson et al., 1996). Microhabitats ameliorate environmental conditions by reducing thermal and desiccation stresses during the low tide period (Gray and Hodgson, 1998). Hence they can be key features for the recruitment and survival of many species of marine molluscs including limpets (e.g. Hawkins and Hartnoll, 1982; Gray and Hodgson, 1998) and snails (e.g. Catesby and McKillup, 1998). This is especially the case for juvenile stages, which show less resistance to environmental stress (Branch and Marsh, 1978). The majority of man-made structures (seawalls, breakwaters, pilings) typically lack the habitat complexity of natural shores and this is widely recognised as the main factor affecting the assemblages they support (Chapman, 2003).

In the present study, we sought a way that conciliates the need to protect coastlines while doing so in a way that can promote the enhancement of exploited stocks. Specifically, we examined the viability of modifications made to coastal structures deployed for coastline protection as a tool to enhance the stocks of the exploited limpet Patella candei. This species is endemic to the Macaronesia where it is heavily exploited for consumption. In the Canary Islands, $P$. candei is virtually extinct due to over-exploitation (Côrte-Real et al., 1996; Navarro et al., 2005). In the Azores P. candei is also widely collected for human consumption, where it has made an important contribution to local economies until the collapse of stocks in the mid 1980s (Hawkins et al., 2000) with negative ecological impacts (Martins et al., 2008a). Since then, the number of limpets has increased slowly in some islands, but still shows clears signs of over-exploitation in the most populated and urbanised ones (e.g. São Miguel). We therefore tested the hypothesis that under the model that microhabitat provision af- fects the distribution and survival of $P$. candei on natural shores, we would predict that in areas of a seawall with experimentally added microhabitats the number of limpets would increase in proportion to the extent of increase in provision of microhabitat and that a greater number of limpets would survive adverse conditions. This study, therefore, evaluates how ecological understanding can be used in modifications of coastal engineering to promote the conservation of an over-exploited species, which has a dominant role in intertidal community structure.

\section{Materials and methods}

\subsection{Study sites}

The Azores archipelago is volcanic by origin and the coast is mainly composed of boulder shores interspersed between rocky platforms. Sandy beaches are restricted to a few sites and are usually small in size. The mean tidal range is approximately $1 \mathrm{~m}$ with a maximum HWS of $1.8 \mathrm{~m}$ above Chartum Datum (CD). The islands are exposed to considerable wave action and the distribution of many intertidal organisms can thus extend upper on the shore. $P$. candei occurs from the lower intertidal to the splash zone at approximately $3 \mathrm{~m}$ above $\mathrm{CD}$. They are, however, more abundant at the upper mid-shore region. Observational work was undertaken on two moderately exposed rocky platforms on the south coast of São Miguel Island $\left(37^{\circ} 50^{\prime} \mathrm{N}, 25^{\circ} 15^{\prime} \mathrm{W}\right)$ : Lagoa and Caloura (see Martins et al., 2008b for assembly description of these sites), whilst the experimental study used a steep seawall consisting of large regular-sized blocks of natural rock at São Roque constructed in 2005. Although the seawall was made up of natural rock (basalt), its surface was smooth and lacked the micro-topographic complexity of the surrounding natural rocky shores (substratum rugosity, estimated as the difference in length of 5 replicate $100 \mathrm{~mm}$ aluminium sheets moulded to the substratum. Seawall $3.1 \pm 0.6 \mathrm{~mm}$ (mean $\pm \mathrm{SE}$ ), and natural shore - $18.5 \pm 1.8 \mathrm{~mm}$. 2way ANOVA: significant main effect of habitat (seawall vs. natural shore) $F_{1,17}$ (pooled) $=28.87, p<0.001$, Martins unpublished data).

\subsection{Sampling design}

\subsubsection{Observational study}

Patterns of distribution of $P$. candei were examined during May 2006 at two shore heights well within its vertical range of distribution and where its abundance is greatest: at approximately $1.5 \mathrm{~m}$ above Chart Datum (CD) and at approximately $2.2 \mathrm{~m}$ above CD. At each location, three sites, each being a stretch of coast of approximately $20 \mathrm{~m}$ length and separated by at least $50 \mathrm{~m}$ were chosen. At each tidal height, six replicate quadrats of $25 \times 25 \mathrm{~cm}$ were deployed at random within areas of well-drained bedrock. The size of the quadrat considered was as a compromise between the need to sample relatively large number of animals (for analytical purposes) and the size of natural patches free of algae typically found lower on the shore. Smooth areas of rock with clearly identifiable pits were selected on both shores. At the lower sampling level, turf-forming algae monopolised much of the space preventing extensive colonisation by limpets. Therefore, quadrats were located within randomly selected patches that were free of algae. All limpets were counted, measured (maximum shell length) and their position (inside pits vs. open rock) recorded. In the present study, pits were small rounded-shaped holes that clearly protruded into the bedrock with an average depth of 10-12 mm. Many retained water or were dampened when the tide was out. Each quadrat was photographed to estimate the cross-sectional area of the different habitat types (pits vs. open rock). The area of the pits' wall was then added. For this, we considered pits as cylinder-like 
structures and hence the area of the wall could be estimated by multiplying the perimeter of the pit (calculated from the photographs) by pit mean depth. In addition, the depth and maximum length of inhabited pits were also recorded in situ for latter reference.

Mortality was assessed towards the upper shore levels where limpets were most common and where the importance of microhabitats in providing refuge from desiccation was expected to be largest. At each location and within each habitat (pit and rock) twenty limpets ranging in size between 10 and $15 \mathrm{~mm}$ shell length were marked with coloured nail-varnish in March 2007. Ideally, mortality would have been estimated at a range of animal sizes (from recently recruited $0.5 \mathrm{~mm}$ animals up to $40 \mathrm{~mm}$ adults). It was not possible, however, to tag smaller individuals and larger animals were scarce due to exploitation. Marked individuals were relocated fortnightly. During each visit, nearby areas were carefully searched for animals that had migrated. Relocated limpets were counted, whereas missing limpets were considered dead. The layer of nail-varnish was renewed on each visit. The mark done on animals was still clear during each visit suggesting that missing individuals could be attributable to mortality rather than to the fact of marks being washed off.

\subsection{Habitat enhancement}

Following the results of the observational study, which showed the importance of pits for the survival of smaller animals, the use of pit provision in enhancing the recruitment of limpets through modification of coastal engineering was investigated. A topographically simple seawall where pits were generally absent was used, on which two sites were selected $200 \mathrm{~m}$ apart at mid-shore levels.

At each site, 20 areas of $25 \times 25 \mathrm{~cm}$ were marked and randomly assigned to a 2-way orthogonal design including the factors pit size (small and large) and pit density (lesser and greater) with five replicates per treatment. Within each area, eight and sixteen evenly spaced pits were drilled in the lesser and greater density treatments, respectively. The lesser density treatment corresponded to the average pit density recorded in the observational study, while the greater density treatment corresponded to twice that number. Small pits had $12 \mathrm{~mm}$ diameter and $10 \mathrm{~mm}$ depth and covered an area of approximately $6 \%$ and $12 \%$ of the substratum in the lesser and greater density treatments, respectively. Large pits, $24 \mathrm{~mm}$ in diameter and $10 \mathrm{~mm}$ in depth, corresponded to an area of approximately $15 \%$ and $30 \%$ of the substratum in the lesser and greater density treatments. The sizes of experimental pits were within the range of those used by limpets on the two rocky shores and the modal limpet size-class of $10-15 \mathrm{~mm}$ (Martins et al., 2008a) suggests that the sizes of experimental pits were suitable for a majority of the population. Pits were drilled during late November and early December 2006 prior to the main settlement period of limpets. An additional set of five replicate controls (no pits drilled) was randomly selected at each location. Prior to the start of the experiment, the animals present on the exposed surface of the seawall were manually removed from within and approximately $50 \mathrm{~cm}$ around each quadrat. Sampling was done 4 months later in March 2007 and consisted of counting and measuring all limpets within each quadrat and recording their position (pits vs. open rock). Each plot was carefully inspected for small limpets $(<5 \mathrm{~mm})$.

\subsection{Data analysis}

On natural shores, we tested the hypothesis that limpets would be associated with pits using replicated $G$-tests of goodness-of-fit. The additive properties of $G$-tests allowed us to test for generality of the limpet-habitat association among locations and sites. For the advantages of this test over the traditional $\chi^{2}$ tests of goodness-offit see Sokal and Rohlf (1995) and McDonald (2008). Analyses were run separately for the upper and lower shore data. Yates correction was used in individual $G$-tests of goodness-of-fit to correct for small sample sizes (Sokal and Rohlf, 1995; Quinn and Keough, 2002). However, the non-corrected $G$-values were retained for the tests of generality as the Yates correction affect the way $G$-values are added up (McDonald, 2008). For each site, the expected proportions for the test were calculated using the averaged per quadrat area of each habitat.

To test the hypothesis that the limpet-microhabitat association strength would vary over the vertical range of limpet distribution we used analysis of variance (ANOVA) on the per quadrat percentage of inhabiting limpets to the per quadrat pit area ratio. Data were logged prior to the analysis. Data were tested using 3-way mixed model ANOVA with shore height (fixed, two levels), location (random, two levels) and site (random, three levels and nested within location).

Mortality of limpets inhabiting pits and on open rock was compared using the exact binomial test for goodness-of-fit (Sokal and Rohlf, 1995; McDonald, 2008) on the surviving animals after 10weeks. Data were analysed separately for each location.

The Kolmogorov-Smirnov test was used to examine for differences in the size of limpet in pits and on open rock. For this particular test, data were grouped among sites within each location and tidal height.

On the seawall, an ANOVA was used to test the general hypothesis that limpets would aggregate in areas where microhabitats were experimentally added. Since the number of areas with experimental pits (four treatments) was greater than controls, a 2-way asymmetrical ANOVA was used. This was done by using the sum of squares from two independent ANOVAs. One run with all treatments together (one control plus four treatments) and the other run without the control. This allowed the variation associated with controls and that of treatments to be distinguished, which can then be contrasted with one degree of freedom (see Underwood, 1997 for further detail on asymmetrical designs). Thus, a 2-way asymmetrical ANOVA was used with two factors: site (random, two levels) and treatments (fixed). The total number of limpets per quadrat, that is the number of animals inhabiting experimental pits and those on open rock, was used in this analysis. Partitioning of the mean squares among the different treatments (pit size and pit density) was not done, as this was not relevant for the hypothesis being tested. The effects of various treatments in the numbers of inhabiting animals are examined below. Prior to analysis, Cochran's test was used to test for homogeneity of variances and transformations applied where necessary (Underwood, 1997).

To test the hypothesis that pit size and pit density would affect the number of inhabiting limpets a 3-way ANOVA was used with site (random, two levels), pit size (fixed, two levels) and pit density (fixed, two levels). Only limpets that were inside pits were considered for this analysis in contrast to the previous analysis. The different treatments differed in the areal proportion of the quadrat represented by pits, which could affect interpretation of results. To examine if animals were responsive to the area of microhabitat per se the number of limpets inside pits was correlated against the areal proportion of pits per quadrat.

\section{Results}

\subsection{Observational study}

A total of 457 animals were recorded on natural shores. Significant heterogeneity among individual $G$-tests indicated that the ra- 
Table 1

Replicated G-tests of goodness-of-fit testing for the association of Patella candei with microhabitats at three sites within each of two natural shores.

\begin{tabular}{|c|c|c|c|c|c|c|c|}
\hline Shore height & Location & Site & Pits & Rock & df & $G$-value & $p$ \\
\hline \multirow[t]{9}{*}{ Upper } & \multirow[t]{3}{*}{ Lagoa } & 1 & 28 & 14 & 1 & 260.66 & $<0.001$ \\
\hline & & 2 & 19 & 5 & 1 & 232.04 & $<0.001$ \\
\hline & & 3 & 35 & 3 & 1 & 493.17 & $<0.001$ \\
\hline & \multirow[t]{3}{*}{ Caloura } & 1 & 24 & 2 & 1 & 212.30 & $<0.001$ \\
\hline & & 2 & 16 & 3 & 1 & 207.53 & $<0.001$ \\
\hline & & 3 & 31 & 7 & 1 & 389.00 & $<0.001$ \\
\hline & Total & & & & 6 & $1873.01^{\mathrm{a}}$ & $<0.001$ \\
\hline & Pooled & & 153 & 34 & 1 & $1788.93^{a}$ & $<0.001$ \\
\hline & Heterogeneity & & & & 5 & $84.09^{a}$ & $<0.001$ \\
\hline \multirow[t]{9}{*}{ Lower } & \multirow[t]{3}{*}{ Lagoa } & 1 & 35 & 15 & 1 & 392.41 & $<0.001$ \\
\hline & & 2 & 24 & 15 & 1 & 414.97 & $<0.001$ \\
\hline & & 3 & 37 & 25 & 1 & 477.87 & $<0.001$ \\
\hline & \multirow[t]{3}{*}{ Caloura } & 1 & 23 & 2 & 1 & 242.65 & $<0.001$ \\
\hline & & 2 & 48 & 4 & 1 & 875.50 & $<0.001$ \\
\hline & & 3 & 31 & 9 & 1 & 556.78 & $<0.001$ \\
\hline & Total & & & & 6 & $3037.64^{a}$ & $<0.001$ \\
\hline & Pooled & & 198 & 70 & 1 & $2775.98^{a}$ & $<0.001$ \\
\hline & Heterogeneity & & & & 5 & $261.66^{a}$ & $<0.001$ \\
\hline
\end{tabular}

a Yates correction was applied to all tests except where marked. The un-corrected values of individual $G$-tests (not shown) were added to calculate the total $G$-value (McDonald, 2008).

tios differ among sites both at the upper and lower shore levels (Table 1) and hence data could not be analysed for each site separately. Individual tests (sites) showed highly significant $G$-values indicating that limpets were inside pits more frequently than would be expected by chance. Analysis of the limpet-pit association strength (Fig. 1, Table 2) showed that significant variation occurred among sites corroborating the significant heterogeneity found in the previous analysis. There was, however, no significant variation between upper and lower shore levels. Thus, the hypothesis that the importance of microhabitats increases with increasing physical harshness was rejected.

Analysis of limpet mortality showed that the number of relocated limpets decreased more with time for those on open rock in the two locations (Fig. 2). At Lagoa, the difference in numbers of relocated limpets after 10 weeks was significantly different between the two habitats (exact binomial test for goodness-of-fit: $p<0.01$ ) being greater in pits, thus suggesting that animals in pits have reduced mortality. At Caloura, however, the result was not significant (exact binomial test for goodness-of-fit, $p=0.082$ ), although the number of relocated limpets was substantially lower on open rock.
Table 2

ANOVA testing for differences in the Patella candei-pit association strength (per quadrat proportion of inhabiting limpets/per quadrat pit area) upper and lower on the shore.

\begin{tabular}{lrllll}
\hline Source & df & MS & $F$ & $p$ & $F$-ratio \\
\hline Location $=L$ & 1 & 0.0787 & 0.24 & $>0.64$ & $S(L)$ \\
Site $(L)=S(L)$ & 4 & 0.3230 & 3.29 & $<0.05$ & Residual \\
Shore height $=H$ & 1 & 0.0004 & 0.02 & $>0.92$ & $L \times H$ \\
$H \times L$ & 1 & 0.0235 & 0.47 & $=0.53$ & $H \times S(L)$ \\
$H \times S(L)$ & 4 & 0.0498 & 0.51 & $>0.73$ & Residual \\
Residual & 60 & 0.0983 & & & \\
\hline
\end{tabular}

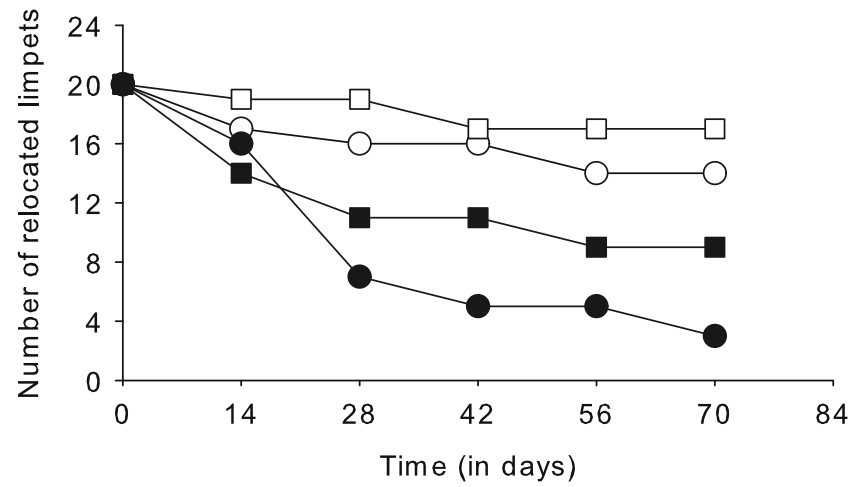

Fig. 2. Number of Patella candei relocated fortnightly in pits (open symbols) and open rock (black symbols) in Lagoa (circles) and Caloura (quadrats).

The size of limpets also differed between habitats being smaller for those inhabiting pits (Fig. 3). Significant variation was recorded lower on the shore at both locations (Lagoa: $D=0.79, p<0.001$, Caloura: $D=0.43, p<0.01)$. Upper on the shore, significant variation was also detected at Lagoa $(D=0.53, p<0.004)$. At Caloura, there were few animals with which to perform the test but it is clear that the size of inhabiting pits was also smaller than those on open rock (Fig. 3). Overall, limpets were smaller inside pits and reached a lower maximum size: mean shell length $( \pm 1 \mathrm{SE})$ inside pits was $12.2 \mathrm{~mm}(0.3)$ compared to $16.9 \mathrm{~mm}(0.5)$ on open rock.

\subsection{Habitat enhancement}

On the seawall, limpets generally aggregated in areas where experimental pits were added (Fig. 4). The overall greater density of limpets in these areas was probably the result of direct recruitment (as indicated by the presence of recently recruited animals)
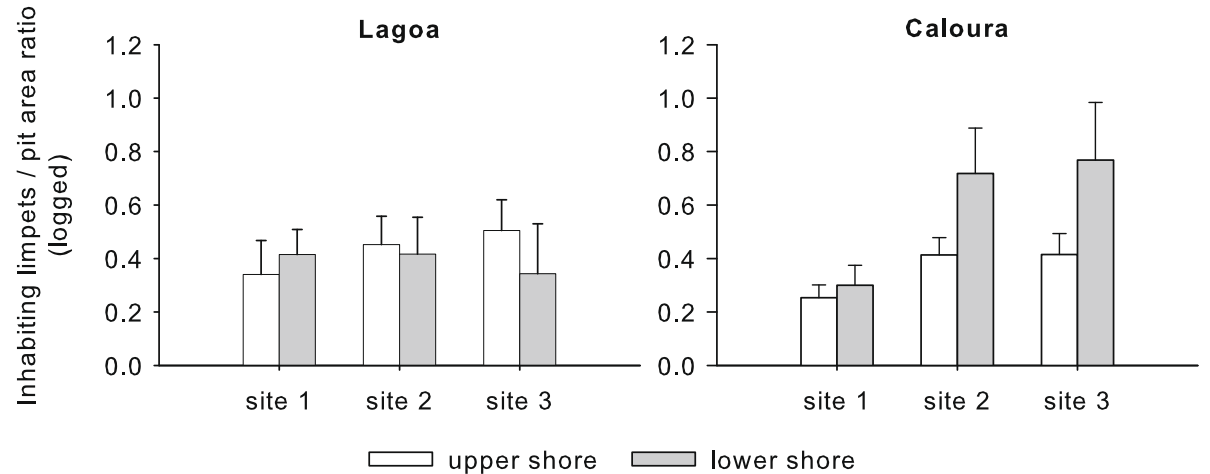

Fig. 1. Ratio of the per quadrat number of Patella candei inhabiting pits to the area of pits on the lower and upper shore levels in the two studied locations. 

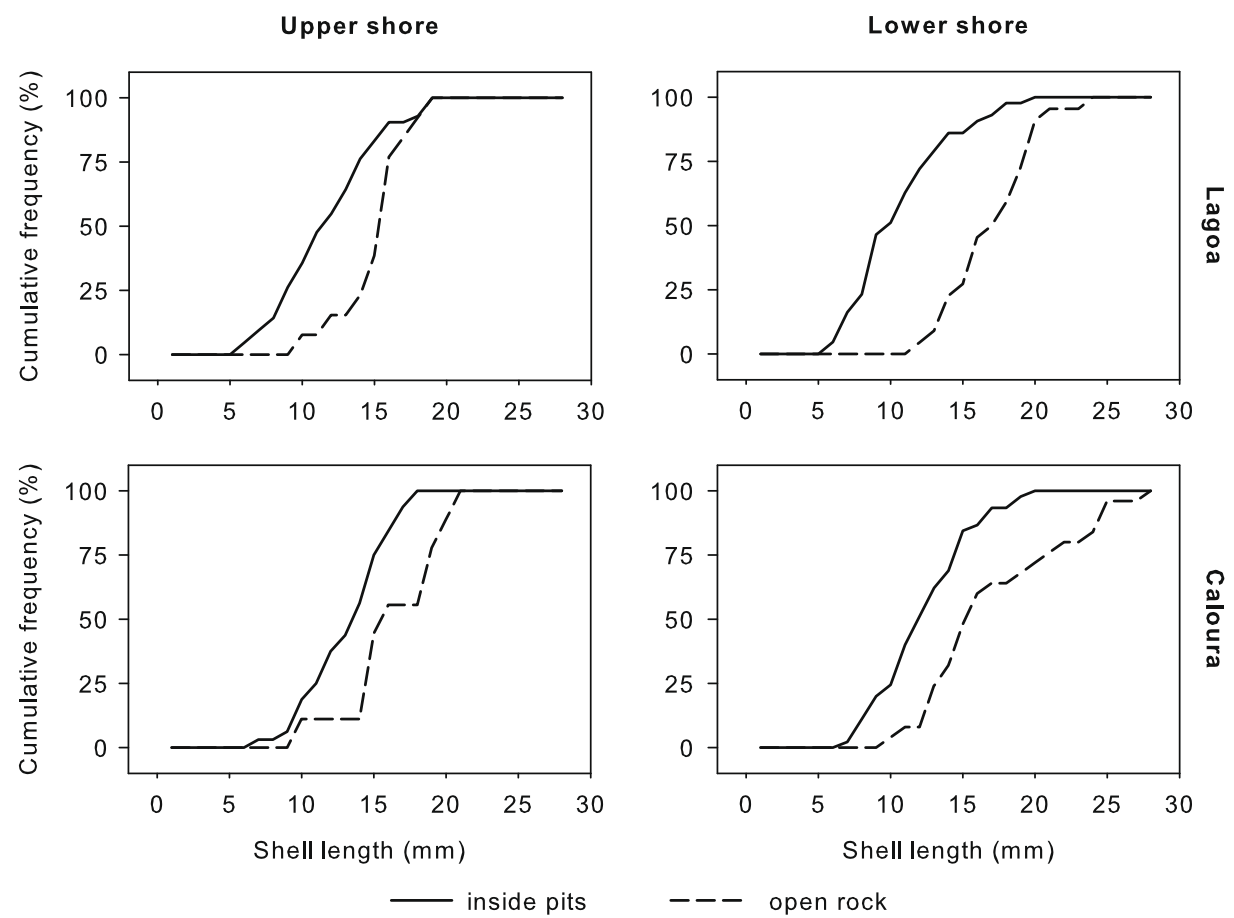

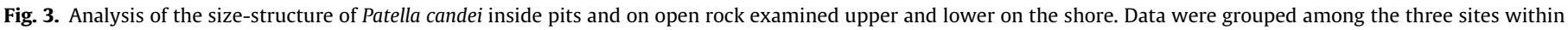
each location.

and immigration (indicated by the presence of larger animals). The numbers of recently recruited $(<5 \mathrm{~mm})$ and immature $(6-10 \mathrm{~mm})$ animals were significantly greater among quadrats with added holes compared to controls although this only became evident at site 2 (Fig. 4 , Table 3 ). At site 1 , there was no measurable recruitment; this was probably the consequence of the bloom of green algae (Ulva spp.) that occurred just after the start of the experiment and which may have been an effect of limpet removal thereby possibly limiting limpet recruitment through pre-emption of space (Benedetti-Cecchi et al., 1999). The larger mature animals $(\geqslant 11 \mathrm{~mm}$ ) also tended to aggregate in areas with experimental pits, but this was not significant (Fig. 4, Table 3) as there was large variability among quadrats. Such variability could be a consequence of natural variation in the abundance of nearby limpets. Larger animals were most likely immigrants from nearby areas (especially the vertical and more protected sides of the boulders where limpets were more common).

The effects of pit size and density on the number of animals inhabiting pits revealed variable results according to size-class. Generally, the number of recently recruited animals (at site 2) increased with increasing pit density, while the abundance of larger mature individuals was limited by pit size (Fig. 5, Table 4). There was no relationship between the number of limpets and the areal proportion of pits per quadrat for both recently recruited and juvenile animals (data not shown), suggesting that the significantly greater number of recruits in the high pit density treatments was not the direct result of increased area of microhabitat per se. In contrast, larger mature animals responded significantly to increased microhabitat area (site $1: F_{1,18}=18.42, r=0.71, p<0.001$; site 2: $\left.F_{1,18}=23.02, r=0.75, p<0.001\right)$. This effect was, however, most pronounced among treatments varying in pit size than among treatments varying in pit density (Fig. 6). For example, increasing the density of large pits meant doubling the area of available pits yet there was no increase in limpet density. This indicates that above a certain area of large pits (between zero and that in the lesser density treatment) addition of larger pits does not increase the number of larger animals.

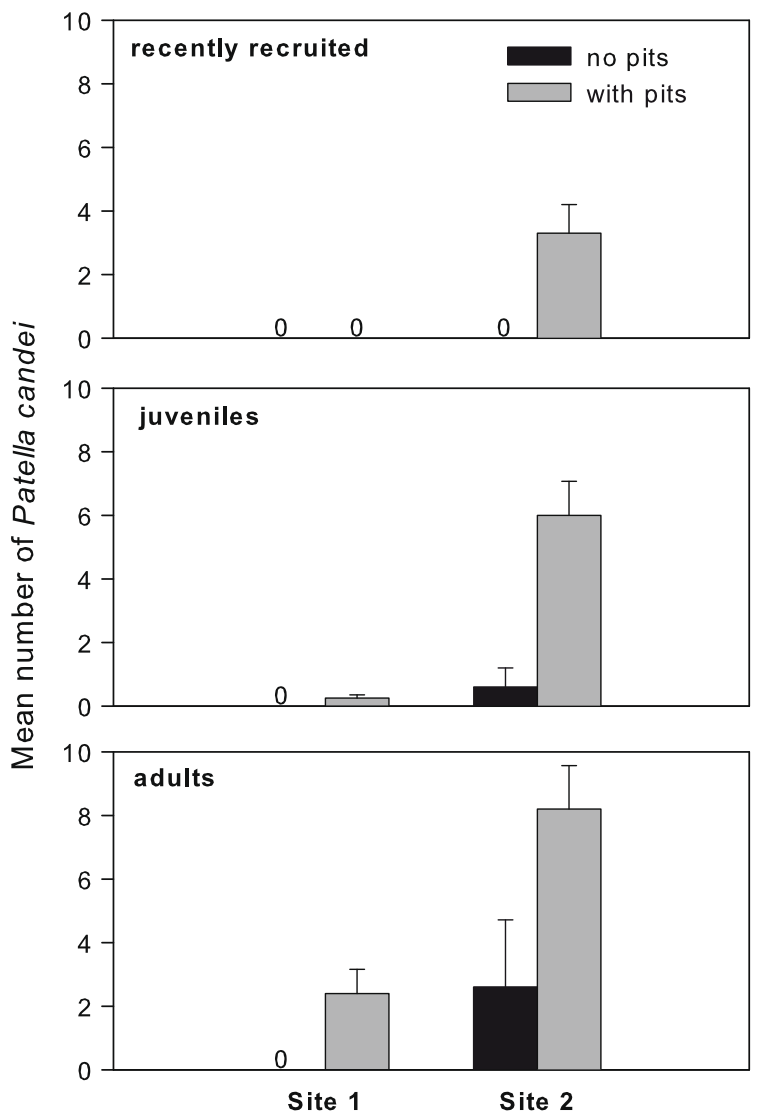

Fig. 4. Mean (+SE) number of Patella candei (includes animals that were both inside pits and on open rock) in treatment (including the four treatments, $n=20$ ) and control areas (no pits, $n=5$ ). 
Table 4

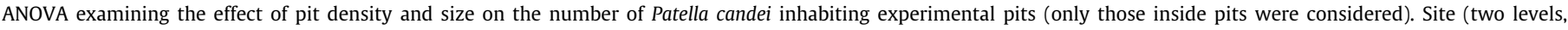
random), pit size (two levels fixed and orthogonal), and pit density (two levels fixed and orthogonal).

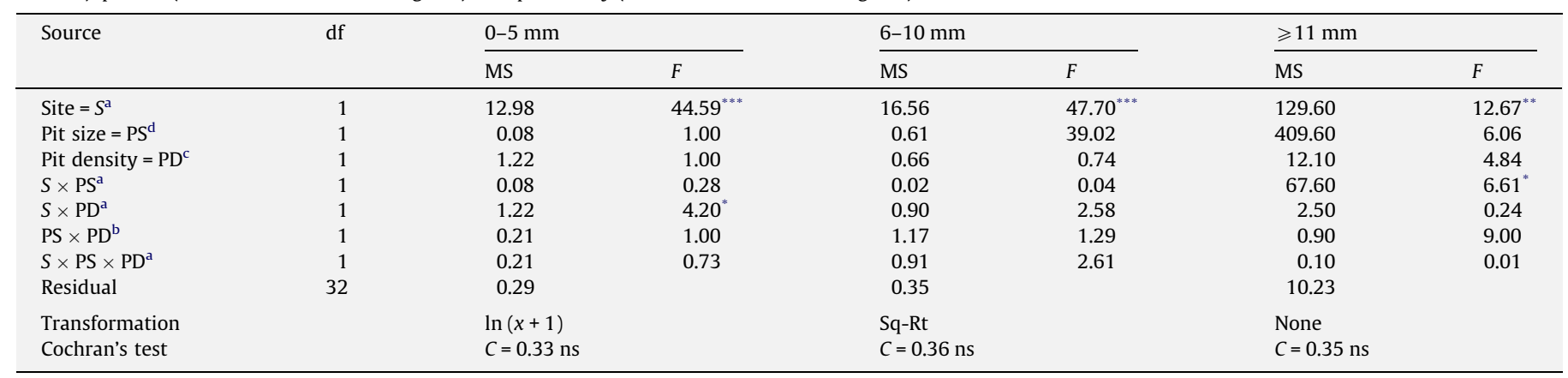

ns: Not significant.

a Tested over the Residual.

b Tested over $S \times$ PS $\times$ PD.

c Tested over $S \times P D$.

d Tested over $S \times$ PS.

$p<0.05$.

$p<0.01$.

$p<0.001$.

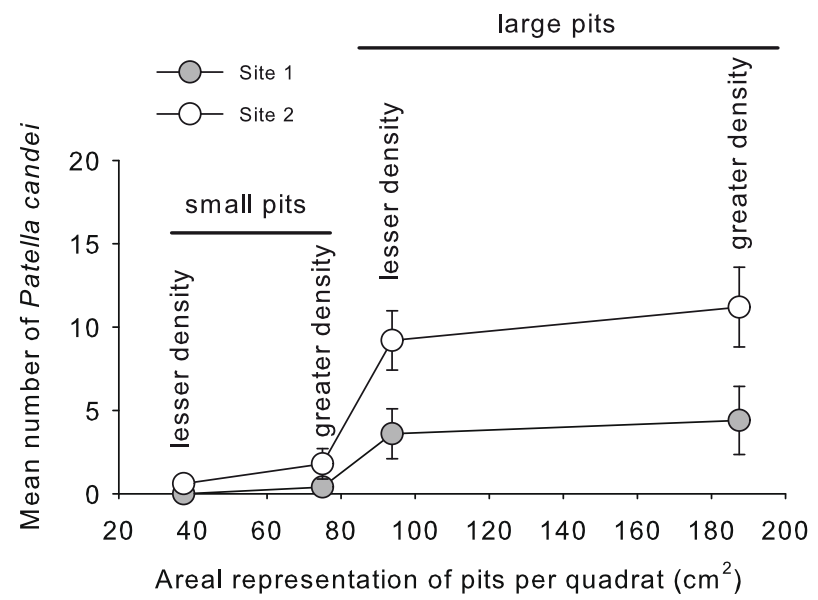

Fig. 6. Mean $( \pm S E, n=5)$ number of the larger mature Patella candei inhabiting pits in relation to the per quadrat areal proportion of pits.

otherwise, biologically impoverished habitats (Moschella et al., 2005; Moreira et al., 2007; Chapman and Blockley, 2009). Our study adds to the existing literature by demonstrating that coastal engineering can also be made in ways that foster the conservation and management of commercially exploited populations. The experimentally provision of microhabitats to a featureless manmade structure resulted, on average, in a 5-fold increase in the abundance of the intertidal limpet $P$. candei compared to control areas. A similar increase in abundance was also found for the edible crab Cancer pagurus by manufacturing holes in the foundations of wave energy devices (Langhamer and Wilhelmsson, 2009). Importantly, compared to natural shores (Martins et al., 2008a), enhanced areas of the seawall also supported 4-times greater abundance of limpets.

The distinction between an aggregative and real effect on population size is paramount to evaluate the success of artificial structures used for enhancing the stocks of commercially exploited species (e.g. Herrnkind et al., 1997; Férnandez et al., 2009). However, for sessile or slow moving species such as limpets it is unlikely that enhanced abundance is a consequence purely of aggregation to a favourable location as can be the case for many mobile fauna such as fish or large decapods. This is supported by our data on the size distribution of animals in enhanced areas; the large number of small animals suggests that microhabitat provision contributed to a local increase in limpet abundance via settlement enhancement, or by reducing the mortality of recently recruited animals.

The modifications made in the present study (see also Moschella et al., 2005; Moreira et al., 2007; Langhamer and Wilhelmsson, 2009) could easily be incorporated into coastal engineering by either moulding pits into the surface of concrete materials or by choosing natural rock with complex topography. If the changes made to the seawall are applied to larger areas or integrated in future coastal engineering, the resulting increase in limpet abundance could have a significant contribution for increasing reproductive output and thus promoting the sustainability of over-exploited populations. As with no-take marine reserves, local enhancement of populations on man-made structures can potentially increase recruitment on natural shores via larval export and this will help maintain the natural structure, which has been modified by loss of limpets through exploitation (see Roberts et al., 2001; Gell and Roberts, 2003 for the effects of marine reserves on adjacent areas). At the community level, consequences may also be expected as suggested by much experimental work that show the important role of patellid limpets in regulating rocky intertidal communities (e.g. Hawkins et al., 1992; Jenkins et al., 2005; Coleman et al., 2006).

The present study focused on only one habitat type and species. The types of natural microhabitats may be as diverse as the number of species in a system and may vary from location to location. From an integrated coastal management point of view aimed at promoting the sustainability of marine natural systems as a whole, the results obtained here are limited. However, as a rule-of-thumb it could be argued that designing man-made structures to mimic local habitats as closely as possible represents the best strategy for mitigating the impacts of these structures on natural systems (Moschella et al., 2005). Increasing habitat heterogeneity - the number of different components of habitats (Matias et al., 2007) - will diversify the set of niches that can be exploited by different species, or within species, by different life-history stages. In contrast, if the purpose is to deliberately enhance the stocks of particular species, then research must be done to examine what habitat enhancements best maximise each species' production. 


\section{Acknowledgments}

This study was conducted in partial fulfilment of a PhD by GMM and funded by Fundação para a Ciência e Tecnologia SFRH/BD/ 22009/2005. RCT was partly supported by funding from PRIMaRE. SJH and SRJ were funded by NERC grant-in-aid to the Marine Biological Association and more recently the Oceans 2025 Programme. The authors are grateful to M.G. Matias and R.P. Couto for their help during the set up of the experimental study. The experiment complies with the laws of the country in which it was performed.

\section{References}

Airoldi, L., Abbiati, M., Beck, M.W., Hawkins, S.J., Jonsson, P.R., Martin, D., Moschella, P.S., Sunderlöf, A., Thompson, R.C., Åberg, P., 2005. An ecological perspective on the deployment and design of low-crested and other hard coastal defence structures. Coastal Engineering 52, 1073-1087.

Bartley, D.M., Bondad-Reantaso, M.G., Subasinghe, R.P., 2006. A risk analysis framework for aquatic animal health management in marine stock enhancement programmes. Fisheries Research 80, 28-36.

Bell, J.D., Bartley, D.M., Lorenzen, K., Loneragan, N.R., 2006. Restocking and stock enhancement of coastal fisheries: potential, problems and progress. Fisheries Research 80, 1-8.

Benedetti-Cecchi, L., Menconi, M., Cinelli, F., 1999. Pre-emption of the substratum and the maintenance of spatial pattern on a rocky shore in the northwest Mediterranean. Marine Ecology Progress Series 181, 13-23.

Bertness, M.D., Garrity, S.D., Levings, S.C., 1981. Predation pressure and gastropod foraging: a tropical-temperate comparison. Evolution 35, 995-1007.

Booth, J.D., Cox, O., 2003. Marine fisheries enhancement in New Zealand: our perspective. New Zealand Journal of Marine and Freshwater Research 37, 673690.

Botsford, L.W., Castilla, J.C., Peterson, C.H., 1997. The management of fisheries and marine ecosystems. Science 277, 509-515.

Branch, G.M., Marsh, A.C., 1978. Tenacity and shell shape in six Patella species: adaptive features. Journal of Experimental Marine Biology and Ecology 34, 111130.

Briones-Fourzán, P., Lozano-Álvarez, E., Negrete-Soto, F., Barradas-Ortiz, C., 2007. Enhancement of juvenile Caribbean spiny lobsters: an evaluation of changes in multiple response variables with the addition of large artificial shelters. Oecologia 151, 401-416.

Bros, W.E., 1987. Effects of removing or adding structure (barnacle shells) on recruitment to a fouling community in Tampa Bay, Florida. Journal of Experimental Marine Biology and Ecology 105, 275-296.

Butler, M.J., Herrnkind, W.F., 1997. A test of recruitment limitation and the potential for artificial enhancement of spiny lobster (Panulirus argus) populations in Florida. Canadian Journal of Fisheries and Aquatic Sciences 54, 452-463.

Castilla, J.C., 2000. Roles of experimental marine ecology in coastal management and conservation. Journal of Experimental Marine Biology and Ecology 250, 321.

Catesby, S.M., McKillup, S.C., 1998. The importance of crevices to the intertidal snail Littoraria articulate (Philippi) in a tropical mangrove forest. Hydrobiologia 367. 131-138.

Chapman, M.G., 1994. Small-scale patterns of distribution and size-structure of the intertidal littotinid Littorina unifasciata (Gastropoda: Littorinidae) in New South Wales. Journal of Marine and Freshwater Research 45, 635-652.

Chapman, M.G., 2003. Paucity of mobile species on constructed seawalls: effects of urbanization on biodiversity. Marine Ecology Progress Series 264, 21-29.

Chapman, M.G., 2006. Intertidal seawalls as habitats for molluscs. Journal of Molluscan Studies 72, 247-257.

Chapman, M.G., Blockley, D.J., 2009. Engineering novel habitats on urban infrastructure to increase intertidal biodiversity. Oecologia 161, 625-635.

Chapman, M.G., Bulleri, F., 2003. Intertidal seawalls-new features of landscape in intertidal environments. Landscape and Urban Planning 62, 159-172.

Choi, C.G., Takeuchi, Y., Terawaki, T., 2002. Ecology of seaweed beds on two types of artificial reef. Journal of Applied Phycology 14, 343-349.

Clynick, B.G., Chapman, M.G., Underwood, A.J., 2008. Fish assemblages associated with urban structures and natural reefs in Sydney, Australia. Austral Ecology 33 $140-150$.

Coleman, R.A., Underwood, A.J., Benedetti-Cecchi, L., Åberg, P., Arenas, F., Arrontes, J., Castro, J., Hartnoll, R.G., Jenkins, S.R., Paula, J., Della Santina, P., Hawkins, S.J., 2006. A continental scale evaluation of the role of limpet grazing on rocky shores. Journal of Animal Ecology 147, 556-564.

Côrte-Real, H.B., Hawkins, S.J., Thorpe, J.P., 1996. Population differentiation and taxonomic status of the exploited limpet Patella candei in the Macaronesian Islands (Azores, Madeira, Canaries). Marine Biology 125, 141-152.

Crowe, T., 1996. Different effects of microhabitat fragmentation on patterns of dispersal of an intertidal gastropod in two habitats. Journal of Experimental Marine Biology and Ecology 206, 83-107.

De Wolf, H., Backeljau, T., Medeiros, R., Verhagen, R., 1997. Microgeographical shell variation in Littorina striata, a planktonic developing periwinkle. Marine Biology 129, 331-342.
Fairweather, P.G., 1988. Movements of intertidal whelks (Morula marginalba and Thais orbita) in relation to availability of prey and shelter. Marine Biology 100, 63-68.

Fairweather, P.G., Underwood, A.J., Moran, M.J., 1984. Preliminary investigations of predation by the whelk Morula marginalba. Marine Ecology Progress Series 17, $143-156$.

Férnandez, T.V., D’Anna, G., Badalamenti, F., Pérez-Ruzafa, A., 2009. Effect of simulated macroalgae on the fish assemblage associated with a reef system. Journal of Experimental Marine Biology and Ecology 367, 7-16.

Garrity, S.D., 1984. Some adaptations of gastropods to physical stress on a tropical rocky shore. Ecology 65, 559-574.

Gell, F.R., Roberts, C.M., 2003. Benefits beyond boundaries: the fishery effects of marine reserves. Trends in Ecology and Evolution 18, 448-455.

Gray, D.R., Hodgson, A.N., 1998. Foraging and homing behaviour in the high-shore, crevice-dwelling limpet Helcion pectunculus (Prosobranchia: Patellidae). Marine Biology 132, 283-294.

Harley, C.D.G., 2003. Abiotic stress and herbivory interact to set range limits across a two-dimensional stress gradient. Ecology 84, 1477-1488.

Hawkins, S.J., Hartnoll, R.G., 1982. The influence of barnacle cover on the numbers, growth and behaviour of Patella vulgata on a vertical pier. Journal of the Marine Biological Association of the United Kingdom 62, 855-867.

Hawkins, S.J., Côrte-Real, H.B.S.M., Martins, H.R., Santos, R.S., Frias-Martins, A.M., 1990. A note on the identity of Patella in the Azores. Açoreana (Suppl.), 167173.

Hawkins, S.J., Hartnoll, R.G., Kain, J.M., Norton, T.A., 1992. Plant-animal interactions on hard substrata in the North-East Atlantic. In: John, D.M., Hawkins, S.J., Price, J.H. (Eds.), Plant-Animal Interactions in the Marine Benthos. Clarendon Press, Oxford, pp. 1-32.

Hawkins, S.J., Côrte-Real, H.B.S.M., Pannacciulli, F.G., Weber, L.C., Bishop, J.D.D. 2000. Thoughts on the ecology and evolution of the intertidal biota of the Azores and other Atlantic Islands. Hydrobiologia 440, 3-17.

Herrnkind, W.F., Butler, M.J., Hunt, J.H., 1997. Can artificial habitats that mimic natural structures enhance recruitment of Caribbean spiny lobster? Fisheries 22, 24-27.

Jenkins, S.R., Coleman, R.A., Della Santina, P., Hawkins, S.J., Burrows, M.T., Hartnoll R.G., 2005. Regional scale effects in the determinism of grazing effects in the rocky intertidal. Marine Ecology Progress Series 287, 77-86.

Jones, K.M.M., Boulding, E.G., 1999. State-dependent habitat selection by an intertidal snail: the cost of selecting a physically stressful environment Journal of Experimental Marine Biology and Ecology 242, 149-177.

Kelaher, B.P., Chapman, M.G., Underwood, A.J., 1998. Changes in benthic assemblages near boardwalks in temperate urban mangrove forests. Journal of Experimental Marine Biology and Ecology 228, 291-307.

Langhamer, O., Wilhelmsson, D., 2009. Colonisation of fish and crabs of wave energy foundations and the effects of manufactured holes - a field experiment. Marine Environmental Research 68, 151-157.

Leitão, F., Santos, M.N., Erzini, K., Monteiro, C.C., 2008. Fish assemblages and rapid colonization of an artificial reef off the Algarve coast (Southern Portugal). Marine Ecology 29, 435-448.

Lewis, J.R., 1964. The Ecology of Rocky Shores. English Universities Press, London.

Lowell, R.B., 1984. Desiccation of intertidal limpets: effects of shell size, fit to substratum, and shape. Journal of Experimental Marine Biology and Ecology 77, 197-207.

Martin, D., Bertasi, F., Colangelo, M.A., Vries, M., Frost, M., Hawkins, S.J., Macpherson, E., Moschella, P., Satta, M.P., Thompson, R.C., Ceccherelli, V.U., 2005. Ecological impacts of coastal defence structures on sediment and mobile fauna: evaluating and forecasting consequences of unavoidable modifications of native habitats. Coastal Engineering 52, 1027-1051.

Martins, G.M., Jenkins, S.R., Hawkins, S.J., Neto, A.I., Thompson, R.C., 2008a Exploitation of rocky intertidal grazers: population status and potential impacts on community structure and functioning. Aquatic Biology 3, 1-10.

Martins, G.M., Thompson, R.C., Hawkins, S.J., Neto, A.I., Jenkins, S.R., 2008b. Rocky intertidal community structure in oceanic islands: scales of spatial variability. Marine Ecology Progress Series 356, 15-24.

Martins, G.M., Amaral, A.F., Wallenstein, F.M., Neto, A.I., 2009. Influence of a breakwater on nearby rocky intertidal community structure. Marine Environmental Research 67, 237-245.

Matias, M.G., Underwood, A.J., Coleman, R.A., 2007. Interactions of components of habitats alter composition and variability of assemblages. Journal of Animal Ecology 76, 986-994.

McDonald, J.H., 2008. Handbook of Biological Statistics. Sparky House Publishing, Baltimore.

McMahon, R.F., 1990. Thermal tolerance, evaporative water loss, air-water oxygen consumption and zonation of intertidal prosobranchs: a new synthesis. Hydrobiologia 193, 241-260.

Moreira, J., Chapman, M.G., Underwood, A.J., 2007. Maintenance of chitons on seawalls using crevices on sandstone blocks as habitat in Sydney Harbour Australia. Journal of Experimental Marine Biology and Ecology 347, 134-143.

Moschella, P.S., Abbiati, M., Åberg, P., Airoldi, L., Anderson, J.M., Bacchiocchi, F., Bulleri, F., Dinesen, G.E., Frost, M., Gacia, E., Granhag, L., Jonsson, P.R., Satta, M.P., Sundelöf, A., Thompson, R.C., Hawkins, S.J., 2005. Low-crested coastal defence structures as artificial habitats for marine life: using ecological criteria in design. Coastal Engineering 52, 1053-1071.

Navarro, P.G., Ramírez, R., Tuya, F., Fernandez-Gil, C., Sanchez-Jerez, P., Haroun, R.J., 2005. Hierarchical analysis of spatial distribution patterns of patellid limpets in the Canary Islands. Journal of Molluscan Studies 71, 67-73. 
Oyamada, K., Tsukidate, M., Watanabe, K., Takahashi, T., Isoo, T., Terawaki, T., 2008. A field test of porous carbonated blocks used as artificial reef in seaweed beds of Ecklonia cava. Journal of Applied Phycology 20, 863-868.

Quinn, G.P., Keough, M.J., 2002. Experimental Design and Data Analysis for Biologists. Cambridge University Press, Cambridge.

Roberts, C.M., Bohnsack, J.A., Gell, F., Hawkins, J.P., Goodridge, R., 2001. Effects of marine reserves on adjacent fisheries. Science 294, 1920-1923.

Santos, M.N., Monteiro, C.C., 1997. The Olhão artificial reef system (South Portugal): fish assemblages and fishing yield. Fisheries Research 30, 33-41.

Silva, A.C.F., Hawkins, S.J., Boaventura, D.M., Thompson, R.C., 2008. Predation by small mobile aquatic predators regulates populations of the intertidal limpet Patella vulgata (L.). Journal of Experimental Marine Biology and Ecology 367, 259-265.

Sokal, R.R., Rohlf, F.J., 1995. Biometry: The Principles and Practice of Statistics in Biological Research, third ed. W.H. Freeman, New York.

Thompson, R.C., Wilson, B.J., Tobin, M.L., Hill, A.S., Hawkins, S.J., 1996. Biological generated habitat provision and diversity of rocky shore organisms at a hierarchy of spatial scales. Journal of Experimental Marine Biology and Ecology 202, 73-84.

Thompson, R.C., Crowe, T.P., Hawkins, S.J., 2002. Rocky intertidal communities: past environmental changes, present status and predictions for the next 25 years. Environmental Conservation 29, 168-191.
Underwood, A.J., 1995. Ecological research and (and research into) environmental management. Ecological Applications 5, 232-247.

Underwood, A.J., 1997. Experiments in Ecology: Their Logical Design and Interpretation Using Analysis of Variance. Cambridge University Press, Cambridge.

Underwood, A.J., 1998. Relationships between ecological research and environmental management. Landscape and Urban Planning 40, 123-130.

Underwood, A.J., 2004. Landing on one's foot: small-scale topographic features of habitat and the dispersion of juvenile intertidal gastropods. Marine Ecology Progress Series 268, 173-182.

Underwood, A.J., McFadyen, K.E., 1983. Ecology of the intertidal snail, Littorina acufispira (Smith). Journal of Experimental Marine Biology and Ecology 66, 169197.

Vermeij, G.J., 1973. Morphological patterns in high-intertidal gastropods: adaptive strategies and their limitations. Marine Biology 20, 319-346.

Williams, G.A., Morritt, D., 1995. Habitat partitioning and thermal tolerance in a tropical limpet, Cellana grata. Marine Ecology Progress Series 124, 89103.

Wolcott, T.G., 1973. Physiological ecology and intertidal zonation in limpets (Acmaea): a critical look at limiting factors. Biological Bulletin 145, 389422 